Conference Proceedings - Long Paper

\title{
Integration and Instability: the resilience of urban refugees in Dar es Salaam, Tanzania
}

\author{
Aisling O'Loghlen ${ }^{1}$ \\ Building, Newcastle upon Tyne, NE1 8ST \\ E-Mail: aisling.ologhlen@ nortumbria.ac.uk \\ * Aisling O’Loghlen; Tel.: +44 - (0)191 - 349 - 5081
}

${ }^{1}$ Northumbria University Newcastle, Department of Arts, Design and Social Sciences / Lipman

\begin{abstract}
Recent global trends have seen a steady increase in both the levels of urbanisation and forced displacement worldwide. This nexus of challenges is evident in the Great Lakes region of sub-Saharan Africa, where protracted conflicts have produced large populations of refugees, in tandem with the rapid growth of cities such as Dar es Salaam, Tanzania. For an urban municipality, the presence of a burgeoning urban refugee population in Dar es Salaam presents a number of difficulties. As a city with 5.6\% annual growth, Tanzania's primary city is already struggling to contend with migration from rural areas, poor infrastructure, the effects of climate change and widespread informality. To successfully integrate refugees into a host community with whom they will have to complete with for employment and access to basic services requires the municipality to support the refugees' own resilience strategies, and facilitate wider community resilience through urban institutions. This paper will examine what types of resilience strategies have emerged, both at an individual and institutional level in Dar es Salaam, as a consequence of the urbanisation-displacement nexus.
\end{abstract}

Keywords: urban refugee, displacement, Dar es Salaam, Tanzania, integration

\section{Introduction}

The displacement of large swathes of people globally has become a more common occurrence in recent decades, as has the urbanisation of these displacements. Crisp et. al. (2012) note numerous cities which in recent years have seen a significant increase in population due to an influx of refugees and / or internally displaced people (IDPs) - including Goma (The Democratic Republic of Congo), Kampala 
(Uganda) and Kuala Lumpur (Malaysia) to name but a few. A well-documented discourse exists on displacement of both refugees and IDPs (Vincent and Sorensen, 2001; Jacobsen, 2008, Beall and Fox 2009; Thomas-Jensen, 2011; Pantuliano et. al, 2012) which discuss the debates surrounding the causes and effects of the respective populations, and both government and the humanitarian communities responding to displacement crises to date. In relation to urban displacement specifically, Pantuliano et. al (2012) note that "there has been far less discussion in academic, policy and operational literature on how to respond to urban-based complex emergencies. In particular, the links between conflict / violenceinduced displacement and acute vulnerability have been poorly addressed" (pg 52). She also makes the salient point that those displaced sections of the community frequently face similar challenges to the host communities, often consisting of urban poor with whom they compete for scarce resources such as accessing basic services. Crisp et. al. (2012) supports the point that more research is required to delve into the links between rapid urbanisation and displaced peoples' settlements and acknowledges that the humanitarian community as a whole has struggled to cope with the refugee influx - he describes them succinctly as 'a messy beneficiary'. With this, he refers to the fact that the enumeration and profiling of refugees in urban areas is an excessively costly procedure requiring considerable resources. The fact that refugee populations are often hidden in urban areas, results in their needs not being acknowledged by local governments or development organisations. Although the urban poor population may be more visible, they too are generally neglected, lacking the political voice to attract the attention of those in power.

Within the context of this urbanisation of forced migration, this paper introduces a conceptual framework for urban displacement incorporating the concepts of the right to the city, asset vulnerability and displacement. It does so using data collected on urban refugees and Tanzanian urban poor in Dar es Salaam, the primary city of Tanzania and one of the fastest growing cities in the world. The findings from this fieldwork provide the basis for developing the conceptual framework discussed in the following section.

\section{A conceptual framework}

This section presents the diagrammatic representation of the nexus of asset vulnerability, displacement and the right to the city (Figure 1), then proceeds to discuss these concepts in more depth. This nexus acts as a starting point to begin to bridge the theoretical / practical divide which often exists in urban studies - the interaction of the theoretical right to the city with the more concrete asset vulnerability framework within the context of a space where urban vulnerable populations reside. In this case the populations in question are the Tanzanian urban poor and urban refugees of Dar es Salaam. As noted by Boniburini - "material practise needs imaginaries to envisage comprehensive and complex counterhegemonic projects, and imaginaries need the experience gained by material practices if eventually they want to materialise these" (2013, p. 27). What Boniburini is stating is that, simply put, theory and practice cannot exist without each other, and so by combining both as this paper attempts to do, a complex picture emerges (Figure 1) of the forces at work in the urban landscape.

An examination of Figure 1 shows that it represents the urban refugee and Tanzanian urban poor populations at the household level, adopting an assets-based approach, while at the state level a rightsbased approach is adopted. The Tanzanians and urban refugees compete for assets at the household level 
and reduce their vulnerability by building a portfolio of financial, social, human, natural and physical capital, as developed by Moser (1998), DFID (1999) and others. At the macro/state level however, this vulnerability is driven and increased by greater levels of displacement and informal urbanisation. The urban refugees and Tanzanians can have an impact on these drivers through the accumulation of political capital, which allows them the opportunity to influence institutions which develop laws, policies, and affect culture, thereby gaining access to the "right to the city". Therefore, the intangible right to the city must be translated into real rights, which can be realised and defended by both groups. Legislation in itself is not sufficient - while rights may exist on paper, they are worthless if people cannot claim them. In the case of refugees for example, Tanzania is a signatory of the 1951 Convention Relating to the Status of Refugees and its Related Protocol (Chiasson, 2015), which affords refugees the right to freedom of movement. However, in reality refugees are not permitted to exercise this right and are forced to reside in camps in western Tanzania. The majority of refugees that make their way to Dar es Salaam are doing so without permission from the relevant authorities and attempting to exercise their right to the city in spite of the fact that according to legislation this right is a given.

Asset-based approaches tend to focus attention on the dynamics of wellbeing at the household level, while rights-based approaches often focus at the macro, institutional scale (Moser and Norton 2001; Moser, 2007). In essence the difference lies in the way risk is considered; at the household level risk is a danger, while at the macro level risk can be regarded as an opportunity (Moser, 2007). However, in recent years academics have begun to recognise that that this dichotomy is not beneficial to examining the needs of low income populations, and that in reality there is not a clear-cut separation between the two approaches. Power at both levels is inevitably interlinked, and so both the macro and micro level factors must be considered when developing effective policies in addressing the needs of vulnerable groups, hence their inclusion in the framework. As Conway et. al (2002) note, rights analysis can "provide insights into the distribution of power", while asset vulnerability frameworks can highlight areas where this power is lacking at the household level. The importance of rights which can be realised cannot be understated, indeed "the capacity to make claims effectively is a significant livelihood capability for most people" (Moser and Norton 2001, p. 40). These claims can vary from claims for land, to voting rights, or human rights.

Therefore, rights must exist alongside a space where populations can reduce their vulnerability through the creation of a strong asset portfolio. If these two pillars do not exist in tandem, then it is likely that these populations will remain vulnerable. As Moser and Norton (2001 p. ix) note, "the underlying logic is that a rights/livelihoods perspective enhances social justice, through the application of nondiscrimination and emphasis on 'equitable accountability' of the state to all citizens". It is important to see rights as one mechanism to address the imbalance of power which exists to prevent vulnerable people from acquiring or accumulating assets (Moser and Norton, 2001). From a broader perspective it can act as a mechanism to move vertically the power between micro and macro levels, to gain access to important institutions, as rights do not always equate to power - "Rights seek to contain the flow of power like a bottleneck....but power leaks out, and flows around rights" (Wilson 1997, p. 17). Figure 1 illustrates the complex relationships which exist between the various actors, institutions, and external forces. It indicates not just how political capital can influence institutional structures in accessing the 
Right to the city, but also importantly how poorly development policies and legislation can severely impede this access.

The right to the city

The right to the city was a concept originally constructed by Henri Lefebvre in his 1968 book Le Droit á la Ville, which examined urban dwellers' freedom and access to urban life. Marcuse (2009), describes Lefebvre's right to the city as "a cry and a demand, a cry out of necessity and a demand for something more" (pg 190), stating that the demand of the right to the city comes "from the directly oppressed, the aspiration from the alienated" (Marcuse, 2009 pg 191).

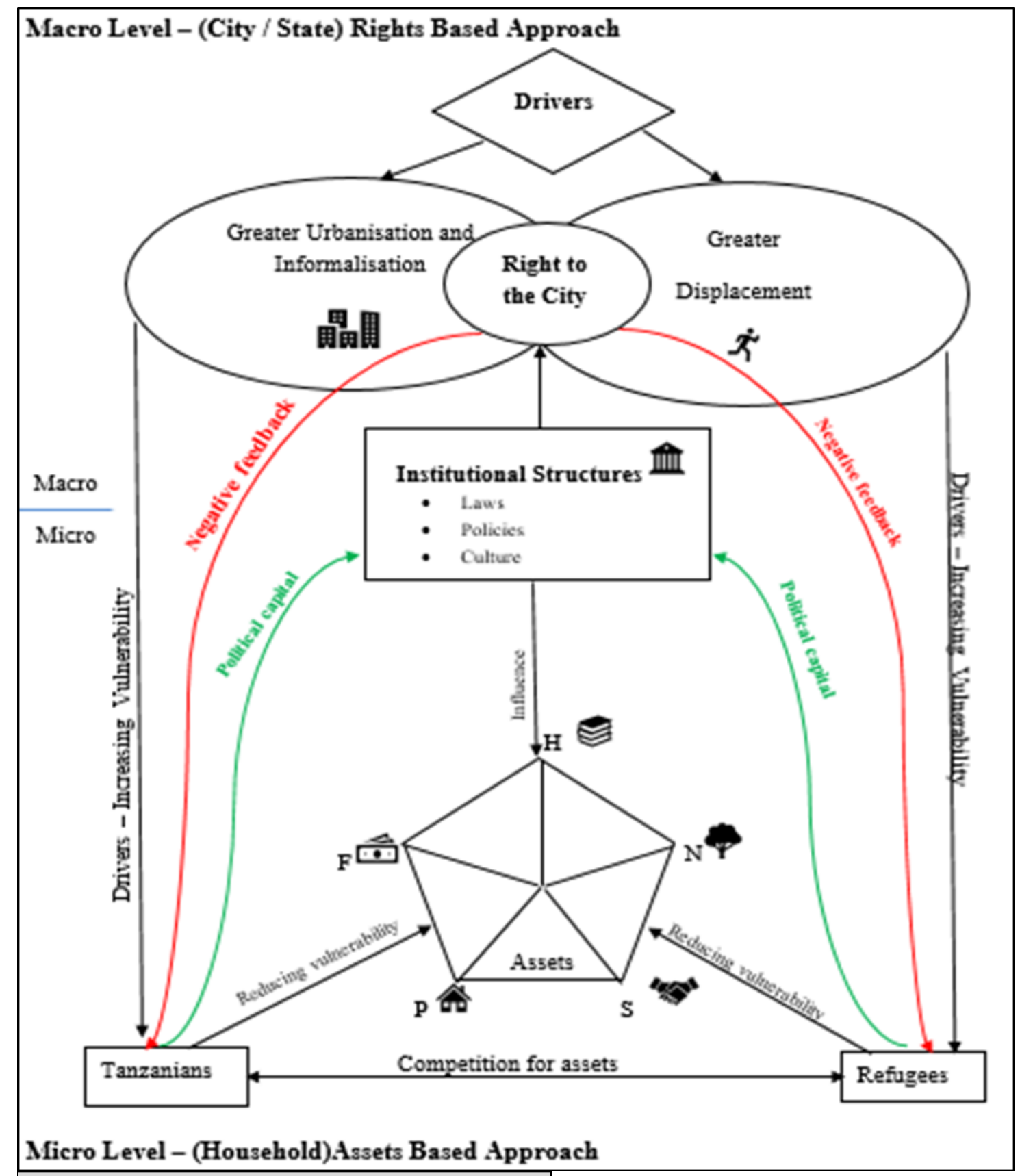

KEY

$\mathrm{H}=$ Human Capital $\mathrm{S}=$ Social Capital

$\mathrm{N}=$ Natural Capital $\mathrm{P}=$ Physical Capital

$\mathrm{F}=$ Financial Capital

Figure 1 . The nexus of asset vulnerability, displacement and the right to the city. 
Source: Author, pentagon adapted from DFID (1999)

This concept has been scrutinised by many authors since Lefebvre's original work: (Boniburini et. al, 2013; Friedmann, 1995; Harvey, 2003; Harvey, 2006; Harvey 2008; Harvey, 2012; Marcuse, 2009; Marcuse 2014; Smith and Jenkins, 2013; Vogiazides, 2012). This breath of scholarship clearly indicates that the right to the city is still very much a valid topic in academia, as different groups, especially the urban poor, fight for their rights to land and basic services. The idea has become quite amorphous, in some cases co-opted and expropriated by various groups claiming that it espouses their claims to the city, and Marcuse (2014) identifies no less than 6 different readings of Lefebvre's original work, each with quite diverse interpretations. The phrase itself has become 'contested territory' (Boniburini 2013, p. 17) as competing factions adopt the concept as an endorsement of their own ideals, often from quite different perspectives. The resurgence of the concept as a 'slogan' for many organisations involved in both human rights and urban development is evident in recent years: the World Charter for the Human Right, along with the European Social Forum have used the concept as a type of "political manifesto" (Boniburini, 2013 pg 19). So too has the World Social Forum through the World Charter for the Right to the City (Institutional Alliance of Inhabitants, 2005), in addition to UNESCO (2006; Brown and Kristiansen, 2009) and UN-Habitat (2010) which have incorporated the concept into their programmes as a rights-based approach. However, reactions to these have been mixed with some viewing the loss of Lefebvre's original radical idea in order to achieve a broad consensus as a weakening of the concept (Boniburini, 2013). Irrespective of whether this is the case, the fact remains that the right to the city is once again at the forefront of discourse on urban development.

For the purposes of the discussion this paper will focus on a 'strategic reading' of Lefebvre's work, as noted by Marcuse (2014). The strategic reading was chosen as it identifies with groups that are the underprivileged and suffering in urban society, prohibited economically or socially from real inclusion in the City. They are simply seeking 'to obtain the benefits of existing city life from which they have been excluded" (Marcuse, 2014 p. 6). It is also acknowledged in adopting this reading that the original writing of Lefebvre took place in a very different context to the modern day so called global South - and the paper acknowledges that "the transference of this concept to different socio political contexts is not direct" (Smith and Jenkins, 2013 pg 139). The development of the urban displacement theoretical framework is furthered by Marcuse's reading of Lefebvre which helps to break down the radical nature of the concept by forming three questions which need to be answered - whose right, what right and what city (Marcuse, 2009).

In this instance, Marcuse's interpretation of Lefebvre also helps to bridge the theoretical / practical divide which often exists in urban studies - the interaction of the sometimes quixotic right to the city and the more concrete asset vulnerability framework will help to allow theory to develop in tandem with practical application in the 'real city', not independently of it (Marcuse, 2009). Indeed, one could argue that this dyad of theory and practice, these linkages, are key to the usefulness of the concept of the right to the city - although Lefebvre's radical idea is ground breaking, it is not enough on its own, it must create a city where not just material needs but where "aspirational needs" are met (Marcuse 2009, p. 193). So it is not sufficient for a refugee to live in a one room house today - the must be able to aspire one day to own their own home. This in turn answers the question of what city? It must be a city to cater for the aspirations of its inhabitants, a point which Lefebvre and Marcuse are both insistent on. In 
addition, it must also be a city that, according to the prevailing analyses of the right to the city, rejects the capitalist system (Marcuse, 2009). It is not possible within the scope of this paper to comprehensively address this point and the surrounding discourse on neoliberalism in relation to the right to the city, but the connection between the two issues must be acknowledged nevertheless. What changes can the city of Dar es Salaam make in the present day, to allow the aspirational visions of Marcuse and Lefebvre to be realised? Herein lies the usefulness of the development of this new conceptual framework based on the nexus of asset vulnerability, the right to the city and displacement. That is, it can begin in some small measure to answer this question.

\section{The asset vulnerability framework}

There exists a large body of work on the related topics of asset vulnerability, sustainable livelihoods, social protection and accumulation, beginning with the work on entitlements of Sen (1981), and developed and supplemented by later work including Chambers and Conway (1992), Chambers (1995), DFID (1999) and Rakodi and Lloyd Jones (2002). This large body of work has led to "conceptual confusions" (Moser, 1998 p.3) and an increasingly complex and interlinked plethora of conceptual frameworks regarding these topics. For the purposes of this paper and for the sake of clarity, the development of theory in this paper is focused on the asset vulnerability framework developed by Moser (1998). Moser's asset vulnerability framework was chosen for this research as it "represents a livelihoods approach to systematically analysing the relationships between the assets and vulnerabilities relevant to the urban poor in the Global South" (Parizeau, 2015 p. 162).

The framework is a useful tool to examine further the strategies adopted by urban refugees and the Tanzanian urban poor. Much work has already been completed on the livelihoods strategies which have been adopted by the urban poor, and the concept is being considered more frequently in the context of urban refugees (see Campbell, 2006; Metcalfe et.al 2011; Pantuliano et. al 2012; Haysom, 2013). The potential benefits and reframing of refugee crises as development opportunities are also linked to this creation of effective livelihoods strategies, as can be seen in the work of academics such as Jacobsen (2002) and Zetter (2014). A caveat is necessary at this point to clarify that in choosing the asset vulnerability framework, and so focusing on the assets defined by Moser, the author is limiting the scope of issues that will be discussed in relation to other urban populations. However, this approach does not assert that the themes examined in this framework are the only relevant issues for the two populations, or even the most important. Given the plethora of concerns that affect the urban poor, some limits were required to allow a more in-depth discussion on the right to the city in this context, and for the reasons outlined above the asset vulnerability framework was considered to be fit for this purpose.

\section{Methods}

Three case study areas were chosen in areas of Dar es Salaam with a high proportion of informal settlements. The locations of these settlements will not be disclosed in order to protect the refugee populations residing in them, many of who live in the city without permission from the Refugee Services Department. A research permit was granted prior to beginning the fieldwork by COSTECH, the Tanzanian Commission for Science and Technology. The three settlements were chosen after lengthy discussions with both Asylum Access Tanzania (AATZ) and the Centre for Community Initiatives 
(CCI), prominent refugee and urban settlement organisations working in Dar es Salaam who acted as research partners on the project. The case study areas were chosen on the basis of the following:

- The settlements were known to have a sizeable refugee population based on previous research work conducted by AATZ (AATZ, 2011) and Ezra Ministries of Tanzania.

- They were accessible during times of flooding, which pose a significant problem during the rainy season as large areas of informal settlements can become almost inaccessible due to poor drainage and infrastructure.

- They had significant numbers of potential participants from both partner organisations living in the area.

- The cooperation of the local mtaa (sub-ward) office was available for entering the settlement area (this was confirmed through the research assistants who made contact with different ward officers).

30 face-to-face semi-structured interviews were conducted with urban refugees and 30 interviews with Tanzania urban poor. In addition, two participatory mapping sessions were held, one with each group. A further 30 interviews were conducted with a mixture of academics, NGO workers and government officials working in relation to urban issues and refugees in Dar es Salaam. These included urban planners, community leaders, UNHCR staff and housing experts. The interviews focused on the roles of different stakeholders and the mechanisms in addressing the problems of rapid urbanisation and forced displacement in sub-Saharan African cities.

\section{Discussion}

Several key points have emerged during the course of this research which have contributed to the final diagram (Figure 1) for the nexus between asset vulnerability, the right to the city and displacement. The first is that some of the main drivers of vulnerability are urbanisation, informalisation and displacement for both groups. The research has also highlighted how this vulnerability exists at both the macro (city/state) level, and the micro (household level) for both groups, as highlighted in the diagram. This vulnerability at household level is then increased by the interactions between groups competing for assets - in the case of this paper the Tanzanian urban poor and refugees. As both groups attempt to reduce their asset vulnerability, their efforts can be influenced from institutions which exist at both the macro and micro levels - from the actions of their local tenth house leader, right up to ministerial level. Laws, policies, programmes and the prevailing culture of institutions in Dar es Salaam and wider Tanzania can have a significant effect on these attempts by groups at the micro level to lessen their day-to-day vulnerability. The research confirms this through examples such as the difficulties in continuing education for children of poor groups, or exploitative nature of the police force in Dar es Salaam in the case of refugees.

The research findings have also indicated that another key component in reducing asset vulnerability for both groups is political capital. It is here where the nexus begins to link the theoretical foundations of the right to the city with the practical applications of the asset vulnerability framework. Through the accumulation of political capital, vulnerable groups could be in a stronger position to influence the institutions which have such a significant effect on their day to day lives. Currently however, in Dar es Salaam both the Tanzanian urban poor and refugee populations have low levels of political capital although they recognise at the household level institutions are failing them, they have no power to gain more knowledge on why this is occurring, or affect real change. This is the crucial connection between the asset vulnerability framework and the right to the city; without political capital asset-poor individuals 
can be actively or passively hindered from full inclusion in city life by urban institutions and governance structures. This capital becomes even more important for two reasons: 1) political capital is often a requirement for "contesting claims related to other assets" (Moser and Norton 2001, p. 19) and 2) much responsibility for social policy has been placed on traditional institutions in developing countries, despite their sometimes considerable limitations (Moser, 2005) such as staff capacity, corruption or limited funding. Moser (1998) using this paradigm shows that there is no single factor which leads to vulnerability, but rather it is a complex matrix of several features from institutions to household make up.

This can be seen from the research findings on the organisational management of many of Dar es Salaam's municipal bodies, who answer only to their own narrow mandates, and seem impervious to any outside pressure (where it exists at all) to improve. This is a key finding because it highlights the what is missing from these organisations is an overarching vision for how Dar es Salaam, 'the City' should develop. The finding conceptualises clearly how Lefebvre's visionary idea of people's right to the city is in fact a necessary concept which must exist in the minds of urban inhabitants before any practical form of it can be produced in reality. While it is easy to identify the concrete examples of why Tanzanians and refugees do not have access to the right to the city, (such as lack of infrastructure or secure employment), it is much more complex to identify that it is in fact a lack of vision which has precipitated these practical problems accumulating.

The development of this nexus of asset vulnerability, displacement and the right to the city has therefore been extremely useful in bringing to light this key point; At the macro level, a clear vision and solid theory is in fact vital for a city to function effectively, and this vision of the right to the city will provide a positive or negative feedback mechanism to the micro level, depending on the aspirations of those in charge of powerful institutions. This feedback can work both ways - as it already does in effectively run cities where inhabitants can pressure urban institutions to make changes they deem necessary. However, this can only occur when inhabitants have sufficient amounts of political capital.

\section{Conclusions}

From the research findings, it has emerged that the idea of a well-functioning Dar es Salaam exists as a chimera in the minds of many of its inhabitants, both the vulnerable populations and those in power in the city's institutions. The litany of problems appears overwhelming; however, this is why the idea of the right to the city is so important. While the right to the city in its purest Lefebrivan form may appear utopian, it is extremely useful as a goal to continually strive for, an ideal which all inhabitants of Dar es Salaam can support and feel invested in - a more inclusive, safer, healthier, more prosperous city, 'my Dar es Salaam'; whatever that means for each individual. Once this vision has been outlined, the practical steps which need to be taken will be much easier to enact at an institutional level, as all inhabitants are clear that whatever the mandate of their individual organisations, they are cognisant that they are working towards the bigger picture of a better Dar es Salaam for all. These institutions can then begin to develop policies collaboratively that reduce asset vulnerability at the household level, combining the practical and theoretical visions of the right to the city.

As with all conceptual frameworks, this approach has its limitations. The challenge of reifying each of the three concepts adequately and then comprehensively synthesising them is considerable. It is 
inevitable that in this process some facets may have become lost in the process; or that the attempt fails to capture any of the concepts sufficiently. In the case of this paper, the author views this output as work which can be built further upon, but that has made the necessary first steps in discussing asset vulnerability, displacement and the right to the city in tandem. It has highlighted the utility of this approach through both the development of the conceptual framework and how this has translated into tangible results. By viewing the development of the nexus (Figure 1) as at iterative process at both the macro and macro level throughout the main body of the paper, a clear picture of the conceptual framework of the linkages emerged.

Confirming the analytical utility of this approach is in of itself a research contribution; as outlined in the introduction of the paper, the issues of forced displacement, rapid urbanisation and the growth of informal settlements are all trends which are predicted continue to grow in the coming years. Therefore, the development of this conceptual framework may act as one step towards attempting to make sense of these phenomena as they unfold, and how best urban policy makers can prepare for the upheaval they will inevitably cause. This paper represents the nascent stages of the discussion, which hopefully can be built upon and expanded by future researchers, just as this paper stands on the work of academics such as Professors Caroline Moser, David Harvey and Roger Zetter, and many others who have contributed a great deal to their respective subject areas.

\section{Acknowledgments}

This research was funded by Heriot-Watt University and the International Growth Centre, Grant Number 1-VCU-VTZA-VXXXX-40113.

\section{Conflict of Interest}

The author declares no conflict of interest.

\section{References and Notes}

Asylum Access Tanzania (AATZ) (2011), No Place Called Home, A Report on Urban Refugees Living in Dar es Salaam. Asylum Access, Dar es Salaam.

Beall, J. and Fox, S., (2009). Cities and Development. Routledge, Abingdon.

Boniburini, I. 2013. As a way of introduction, the "right to the city": practices and imaginaries for rethinking the city. In: Boniburini, I, Le Marie, J., Moretto, L. and Smith, H, editors. The City as a Common Good: Urban Planning and the Right to the city. Brussels: La Cambre Horte; pp. 14 - 43.

Boniburini, I, Le Marie, J., Moretto, L. and Smith, H. (2013) (Editors). The City as a Common Good: Urban Planning and the Right to the city. Brussels: La Cambre Horte.

Brown, A. and Kristiansen, A. (2009) Urban Policies and the Right to the city; Rights, responsibilities and citizenship. Cardiff: Management School of Transformations.

Campbell E.H. (2006). Livelihoods in the Region: Congolese Refugee Livelihoods in Nairobi and the Prospects of Legal, Local Integration. Refugee Survey Quarterly. 25, 93-108. 
Chambers, R. (1995). 'Poverty and livelihoods: whose reality counts?', Environment and Urbanisation, 7(1), 173-204.

Chambers, R. and Conway, G. (1992) "Sustainable Rural Livelihoods: Practical Concepts for the 21st Century” Discussion Paper 296. Brighton: Institute of Development Studies.

Chiasson S. (2015). The State of Freedom of Movement for Refugees in Tanzania: An Overview. [Online] Available from: http://rightsinexile.tumblr.com/post/128143318377/the-state-of-freedom-ofmovement-for-refugees-in (Accessed on 2 February 2016).

Conway T., Moser C., Norton A. and Farrington, J. (2002). Rights and livelihoods approaches: exploring policy dimensions. London: Overseas Development Institute.

Crisp, J., Morris, T. and Refstie, H. (2012) Displacement in urban areas: new challenges, new partnerships. Disasters, 36 (S1), S23-S42.

Department for International Development (DFID) (1999). Sustainable Livelihoods Guidance Sheets. London: Department for International Development.

Friedmann, J. (1995) The right to the city. Society and Nature: The International Journal of Political Ecology, 1 (1), 71-84.

Harvey, D. (2003) The Right to the city. International Journal of Urban and Regional Research, 27 (4), 939 - 941.

Harvey, D. (2006) Neo-Liberalism as Creative Destruction. Geografiska Annaler: Series B, Human Geography. 88 (2), 145-158.

Harvey, D. (2008) The Right to the city. New Left Review, 53, September - October.

Harvey, D. (2012) The Right to the city. Paper for Urban Uprising Symposium New York. [Online]. Available at: http://www.urban-uprising.org/sites/default/files/files/righttothecity.pdf (Accessed: 15 July 2013).

Haysom, S. (2013). Sanctuary in the City? Urban displacement and vulnerability final report. London: Overseas Development Institute.

Institutional Alliance for Inhabitants (2005). World Charter for the Right to the city. [Online]. Available at: http://www.urbanreinventors.net/3/wsf.pdf (Accessed on 02/08/15).

Jacobsen, K. (2002). Can refugees benefit the state? Refugee resources and African statebuilding. The Journal of Modern African Studies, 40 (4), 577 - 596.

Jacobsen, K. (2008) Internal displacement to urban areas: the Tufts-IDMC profiling study. Massachusetts: Tufts University.

Lefebvre, H. (1968) Le droit à la ville. Anthopos, Paris. 
Marcuse, P. (2009) From critical urban theory to the right to the city. City, 13 (2-3), 185-197.

Marcuse P. (2014). Reading the Right to the city. City. 18, 4 - 9.

Metcalfe V., Pavanelloa S. and Prafulla M. (2011). Sanctuary in the city? Urban displacement and vulnerability in Nairobi. London: Overseas Development Institute.

Moser, C. (1998) The Asset Vulnerability Framework: Reassessing Urban Poverty Reduction Strategies. World Development, 26 (1), 1-19.

Moser, C. (2007) Reducing Global Poverty: The Case for Asset Accumulation. Brookings Institution Press, Washington D.C.

Moser, C. (2005) 'Assets, livelihoods and social policy'. Paper presented at the Arusha Conference on "New Frontiers of Social Policy", December 12-15.

Moser, C. and Norton, A. (2001). 'To claim our rights: livelihoods security, human rights and sustainable development', London: Overseas Development Institute (ODI).

O’Loghlen, A. and McWilliams, C. (2017). The nexus of displacement, asset vulnerability and the Right to the city: the case of the refugees and urban poor of Dar es Salaam, Tanzania. International Journal of Urban Sustainable Development, 9 (1), 21 - 45.

Pantuliano, S., Metcalfe, V., Haysom, S., Davey, E. (2012) Urban vulnerability and displacement: a review of current issues. Disasters, 36(S1), S1-S22.

Parizeau K., (2015). When Assets are Vulnerabilities: An Assessment of Informal Recyclers' Livelihood Strategies in Buenos Aires, Argentina. World Development. 67, 161-173.

Rakodi, C. and Lloyd - Jones, T. (2002) Urban Livelihoods - A People - Centred Approach to Reducing Poverty. London: Earthscan.

Sen, A. (1981). Poverty and Famine: An Essay on Entitlements and Deprivation. Oxford University Press: Oxford.

Smith, H. and Jenkins, P. (2013). Urban land access in Sub-Saharan Africa: the right to the city in postwar Angola. In: Boniburini, I, Le Marie, J., Moretto, L. and Smith, H, editors. The City as a Common Good: Urban Planning and the Right to the city. Brussels: La Cambre Horte; pp. 139 - 157.

Thomas-Jensen, C. (2011). Crisis and Opportunity: Protracted Displacement in Sudan. Middle East Institute, May 2011 Edition.

UN-HABITAT (2010). The Right to the city: Bridging the Urban Divide, The Fifth Session of the World Urban Forum. UN-HABITAT, Nairobi.

UNESCO (2006). International Public Debates Urban Policies and the Right to the city. UNESCO, Paris. 
Vincent, M. and Sorensen, B.R. (Eds.), (2001). Caught Between Borders: Response Strategies of the Internally Displaced. London: Pluto Press.

Vogiazides, L., (2012). "Legal empowerment of the poor" versus "right to the city" implications for access to housing in urban Africa. Nordiska Afrikainstitutet, Uppsala.

Wilson RA. (1997). Human rights, culture and context. London: Pluto Press.

Zetter, R. (2014). 'Reframing Displacement Crises as Development Opportunities'. Paper presented at: The Global Initiative on Solutions, Copenhagen Roundtable, 2-3 April 2014; Copenhagen, Denmark. (C) 2018 by the authors; licensee MDPI and IFoU, This article is an open access article distributed under the terms and conditions of the Creative Commons Attribution license. 